\title{
组建近化学类专业本科生综合学习团队的探索
}

\author{
薛斌 \\ 1 上海海洋大学食品学院化学系, 上海 201306 \\ 2 食品科学与工程国家级实验教学示范中心(上海海洋大学), 上海 201306
}

摘要：以生物制药和食品大类等近化学类专业本科生为成员组建旨在提升其综合学习能力的团队。开展基于 “班级 授课” “校内实践” “校外实践” 和 “网络媒介” 的团队建设, 引导团队成员夯实专业基础, 开拓学术视野, 全方 位提升学习和实践能力。在学生学习积极性提升、学习成绩提高、学术性活动的参与度和成功率提高方面获得了初 步成效。

关键词：能力提升；团队教学；实施策略

中图分类号：G64; O6

\section{Exploration on the Establishment of Comprehensive Learning Teams for Undergraduates of Chemistry-Related Majors}

\section{Bin Xue *}

${ }^{1}$ Department of Chemistry, College of Food Science and Technology, Shanghai Ocean University, Shanghai 201306, P. R. China.

${ }^{2}$ National Experimental Teaching Demonstration Center for Food Science and Engineering (Shanghai Ocean University), Shanghai 201306, P. R. China.

\begin{abstract}
A teaching team aiming at improving the students' comprehensive learning ability was constructed with the undergraduates majoring in biological pharmacy and food. The team building based on class teaching, on-campus practice, off-campus practice and network media has been carried out to guide team members to consolidate their professional foundation, expand their academic vision, and improve their learning and practical ability in an all-round way. Initial results have been achieved in improving students' learning enthusiasm, academic performance, participation and success rate in academic activities.
\end{abstract}

Key Words: Ability improvement; Team teaching; Implementation strategy

\section{1 团队组建背景}

“团队学习”或 “合作学习” 是一类基于 “学生为中心”教学理念的教学组织形式, 在基础化 学教育和高等化学教育中多有尝试 ${ }^{[1-5]}$ 。但是, 这类教学模式大多应用于课堂教学过程中, 并未延伸 到课外学习和实践中。高等教育阶段学生的学习和成长, 显然不应该仅局限于课堂上, 需要在知识 接受、知识获取和知识运用等综合学习能力方面得到全面提升。然而, 面对更广阔的知识海洋, 已 经习惯于课堂学习的学生往往无所适从, 无法有效自主学习, 无法把握学习机遇, 无法做到全面提

收稿: 2020-02-06; 录用: 2020-03-03; 网络发表: 2020-03-18

“通讯作者, Email: bxue@shou.edu.cn

基金资助: 2018 年上海海洋大学本科教学改革项目(A1-0201-00-032114) 
升自身综合能力, 这种现象对于普通院校的学生而言显得更为突出。因此, 以 “团队学习” 的教学 模式, 整合资源, 相互激励, 可以对传统课堂教学起到补充作用, 给学生合理 “增负”, 使学生 “忙 起来” , 实施全方位学习和实践, 促进学生以 “学术能力” 为引领的综合学习能力的全面提升。

基于以上认识, 笔者从 2016 学年第一学期开始探索组建近化学类专业本科生综合学习团队。团 队成员包括生物制药和食品大类专业本科生, 以自愿报名为前提, 形成大一学生为主、其他年级学 生为辅的梯队结构, 人数保持在 10 人左右。本着 “因材施教” 和 “学术导向” 原则, 在 “前期调研” 基础上开展包括 “班级授课” “校内实践” “校外实践” 和 “网络媒介” 等 “四个课堂” 在内的团 队建设工作, 目标是开阔近化学类专业学生的学术视野, 提高其综合素质, 为将来继续深造和就业 打下基础。

\section{2 团队组建过程和效果}

\section{1 前期调研}

笔者以生物制药和食品大类专业本科生班主任老师和任课教师的双重身份, 采用课后小范围面 谈方式, 分批次与学生开展面对面交流。了解学生的高中阶段学习、高考志愿填报、生源地和家庭 状况等情况。了解进入大学阶段后, 学生的学习和生活情况, 听取学生对于课堂教学的意见和建议。

了解学生对本科毕业后的憧憬及继续深造的意愿。介绍学习团队建设目的和预期目标, 吸纳团队成 员, 并结合实际情况完善团队成员构成, 构成合理梯队。召开团队建设启动会议, 明确团队建设任 务, 根据团队成员自身学习基础的差异, 提供个性化的学习建议, 征求团队成员意见优化团队活动 方案。

\section{2 第一课堂一班级授课}

笔者以生物制药和食品大类专业本科生进入大学阶段的第一门化学课程 “基础化学(无机及分析 化学)” 为依托, 采取多维度教学模式, 在讲授知识点的同时, 补充以课堂讨论、课堂演讲和短文撰 写等形式, 全面强化学生知识获取和运用能力、口头学术表达能力和书面学术表达能力等多方面素 质的训练 ${ }^{[6]}$ 。使学生了解化学类基础课程与其专业学习、职业发展的关联, 为学生的化学基础课和 专业课学习指明方向, 增强其参与学习团队的意愿。并且注重课程的德育功能, 坚持 “不但授业, 而且传道”, 帮助学生成员树立理想抱负, 寻找个人发展方向, 增强学习动力 ${ }^{[7]}$ 。

第一课堂是教师近距离、较长期观察和了解学生学习状态的重要途径, 也是教师展示个人魅力, 传播团队组建理念的重要途径。兄弟院校同行可以以第一课堂为抓手, 通过与学生的课堂及课后接 触, 积极宣传团队组建的理念和团队活动, 以促进团队建设效果。

\section{3 第二课堂——校内实践}

\subsection{1 团队例会}

以 “基础化学创新实验室” 科研组会为依托举行团队例会, 每两周一次。团队成员通过 “旁听一参 与-主讲” 的次序层层递进, 在教师的点拨下, 了解学科前沿和动态, 开展文献研读、工作汇报、文 章撰写和大学生科技创新项目课题申报等学术实践, 对学生文献阅读、学术讨论、项目申报等多方 面能力开展训练。例如, 笔者曾安排团队成员阅读发表在 Nature 上的 2008 年诺贝尔化学奖获得者 钱永健教授的认告, 并在组会上作汇报, 以此引导他们了解科学家成长经历和与绿色荧光蛋白相关 的知识。

\subsection{2 融入教师科研团队}

组织团队成员参观笔者所在的 “基础化学创新实验室” , 为其介绍笔者所从事的无机纳米材料 的制备和应用的课题背景、特色和前景, 以及与他们所在专业的关联, 积极吸纳他们加入科研团队, 参与到无机纳米结构光催化降解有机污染物和致病性微生物杀灭等课题中来, 体验科研过程, 开阔 学术视野, 训练实验技能。 


\subsection{3 专家座谈}

邀请校内知名专家教授与团队成员开展座谈, 开展 “长辈教育”。例如, 笔者邀请的千人计划 特聘专家, 从自己曾经的医生职业经历谈起, 到辞职赴海外攻读学位的学习经历以及毕业后在国外 企业的工作经历, 再到回国创办生物医药高科技企业的创业经历, 全面回顾自己的成长历程, 畅谈 了在国内外求学的不同感受, 以及对学术界和企业界的不同工作理念和状态的对比, 并结合当前大 学生的学情和自身亲子关系提出相关建议。团队成员谈感受，提问题，与专家教授展开互动。

\subsection{4 应届毕业生座谈}

邀请相关专业优秀应届毕业生与团队成员开展座谈, 开展 “朋辈教育”。受邀毕业生涵盖免试 读研、本专业考研、跨专业考研和就业等类型, 其中包括了免试进入中国科学院大学读研的学生, 考取华东师范大学、同济大学、中国科学院大学硕士研究生的学生, 考取中国政法大学法律硕士的 同学, 进入知名培训机构工作的学生等等。他们分别从大学阶段自身成长经历, 特别是大四阶段的 考研、求职、实习经历入手, 介绍了心路历程, 与团队成员开展了广泛的交流, 为团队成员提供了 中肯的建议, 提供了有用的信息。以此为契机, 团队成员与多位优秀应届毕业生取得了联系, 增加 了学习动力, 明确了努力路径。

兄弟院校同行可以充分发挥自身的科研优势, 以自己的课题组为依托积极开展上述校内实践活 动, 并充分利用身边的资源丰富校内实践活动内容, 例如邀请各级各类的人才计划获得者、各级各 类奖学金获得者、应届优秀毕业生、各行各业的优秀校友, 请他们与团队成员开展互动。网络时代 也为这种交流提供了极大的便利性和可行性, 在线访谈、视频录制、后期网络联系等灵活的形式不 一而足。

\section{4 第三课堂一一校外实践}

以赴校外参观访问为依托, 充分利用兄弟院校及社会上的学术资源, 对校内学术资源形成补充, 进一步开阔学生的学术视野。笔者曾组织团队成员赴上海地区兄弟院校相关化学、药学和生物医学 实验室进行参观, 并与外校老师和学生开展广泛交流。通过活动, 团队成员眼界大开, 学习和深造 的动力增强, 并且与外校老师和学生建立了联系, 为后续的合作打下了基础。此外, 笔者还组织团 队成员赴上海国家会展中心参观中国国际工业博览会, 了解产学研相结合在当前科技创新中的重要 意义，并介绍上海的科技展会资源，鼓励学生走出校园充分利用这些社会资源。

兄弟院校同行可以结合学校所处地域特色、学校所属行业特色以及团队成员专业特色, 寻求并 拓展校外实践资源, 例如联系科技企业、大学科技园、卫生防疫部门、质量监督检验部门等等, 并 以此为依托为团队成员的实习实践搭建桥梁, 也为团队成员的创新创业提供灵感。

\section{5 第四课堂—网络媒介}

创建团队 $\mathrm{QQ}$ 群, 通过网络途径, 介绍团队建设主旨, 解答对于团队建设内容、目的和形式等 方面的疑问, 吸收团队新成员, 创造团队成员交流机会, 发布讲座、竞赛、项目申报等信息。以 $\mathrm{QQ}$ 群、微信公众号和 “科学网” 博客为依托, 突破时间和空间限制, 开展网上师生互动和交流, 并把 团队成员的学习体会通过网络媒介进行推送, 实现成员之间信息共享以及团队建设成果辐射。例如, 笔者创建了 “化无止境” 微信公众号, 不但推送自己的教学和科研体会以及科普短文, 而且推送团 队成员的作品。此外, 还向学生介绍 “科学网” 这一全球华人科学社区, 特别是其中的博客版块, 使团队成员感受并融入科学共同体。

兄弟院校同行还可以将 “在线课程” 等网络媒介教学手段与团队组建结合起来, 充分利用各校 普遍存在的 “网络教学综合平台”、教师网上空间(个人主页)、“雨课堂” 等网络教学平台资源, 开 展更加丰富多彩的网络媒介团队活动。

\section{6 初步成效}

团队成员学习积极性和学习效果明显提升。开展校内外实践活动之后, 团队学生成员撰写感想, 并且通过网络和公众号相互交流。从字里行间可以明显感觉到实践活动对他们的触动及其学习动力 
的提升, 从而实现了课程德育的目标。此外, 团队成员积极加入到本校的科研实验室开展研究工作, 同时有学生还联系外校老师, 准备利用假期参与课题研究。在此基础上, 团队成员的学习效果也得 到明显提升, 取得了优异的成绩, 主要表现为普通奖学金实现全覆盖, 特别是连续 3 年分别有 3 位 团队成员获得国家奖学金, 此外还有 3 位团队成员获得了免试读研资格。

大学生科技创新和学科竞赛的参与度和成功率明显提升。团队成员积极投入到各级别科创项目 的申报中, 组建多支科创协作队伍, 并积极吸纳新成员参与。具体表现在团队成员获得了多项市级、 校级和院级大学生科创项目资助, 还参加了高等数学、大学物理、大学化学实验、计算机应用和英 语笔译等学科竞赛, 并获得了多项奖励。

\section{3 结语}

以上针对近化学类专业本科生开展组建综合学习团队的工作, 体现了教师引导下的学生团队式 学习和实践的优势, 取得了初步的成效, 但是必须认识到人才培养是一个长期的过程, 最终的效果 还需要较长时间的考量。此外, 在未来还有许多团队建设举措有待探索。其中包括, 根据前一阶段 团队成员的表现, 积极调整成员组成, 实行动态管理, 保持团队活力; 结合新时代学情, 积极开拓 团队活动新形式, 以更加创新的姿态开展团队建设, 获得更加良好的反馈和成效; 建立团队建设长 效机制, 并与本科生 “导师制” 相结合, 吸纳更多学生加入学习团队, 扩大建设成效辐射范围, 使 更多有意愿提升自身综合学习能力的学生受益。相信以上团队式学习和实践的探索, 对于广大兄弟 院校特别是普通院校同行具有借鉴价值。

[1] 李鹏鸽, 赵河林. 化学教育, 2011, 32 (5), 23.

[2] 邱绍方. 化学教育, 2013, 34 (9), 32.

[3] 黄文勇. 中学化学教学参考, 2014, No.6, 25 .

[4] 崔风侠, 杜春蕾, 李平, 王燕, 桑瑞兰. 化学教育, 2015, 36 (24), 21.

[5] 喻林萍, 童海霞, 张雄飞, 曾巨澜, 肖忠良, 陈茂龙. 广州化工, 2018, 46 (22), 151.

[6] 薛斌. 大学化学, 2019, 34 (7), 1.

[7] 薛斌. 大学化学, 2018, 33 (12), 28. 